\title{
Financiamento estatais e resultados esportivos: o caso do atletismo no Brasil
}

State funding and sporting results: the case of athletics in Brazil

\author{
Rafael Gomes Sentone ${ }^{1, *}$ \\ Isabelle Plociniak Costa ${ }^{1}$ \\ Camile Luciane da Silva ${ }^{1}$ \\ André Felipe Caregnato \\ Fernando Renato Cavichiolli ${ }^{1}$
}

\section{Resumo:}

O esporte está representado ao longo da história como sombra do desenvolvimento social do ser humano numa relação muito íntima entre política e seu processo de desportivização. Se hoje o Brasil se apresenta como país emergente no mundo também o faz no esporte, observado em atletas de destaque em modalidades de natação, atletismo, judô e outras. Partindo desta questão central o presente estudo objetiva buscar relações entre Esporte de Alto Rendimento (EAR) no Brasil relacionando com resultados esportivos e investimento aos atletas através de políticas públicas do Governo Federal como o Bolsa Atleta. Utilizou-se a prova de $100 \mathrm{~m}$ rasos para entender o processo pelo qual os atletas passaram no ranking da Confederação Brasileira de Atletismo (CBAt) até galgarem a posição de destaque nacional que ocupam. Os 1181 dados coletados no período de 16 anos revelaram que a maioria dos atletas obtiveram seus melhores índices da carreira no ranking da CBAt também quando foram contemplados com o subsídio do Bolsa Atleta.

Palavras-chave: política pública, atletismo, esporte.

Afiliação dos autores

1Universidade Federal do Paraná, Curitiba, Paraná, Brasil.

*Autor correspondente

Rua Tenente Djalma Dutra, 1257 apto 901, Centro, São José dos Pinhais, Paraná, Brasil. e-mail: sentoneforest@hotmail.com

Conflito de interesses

Os autores declararam não haver conflito de interesses.

Processo de arbitragem

Recebido: 20/06/2018 Aprovado: 10/12/2018 


\section{Introdução}

A proposta do presente texto visa complementar os estudos realizados pela Universidade Federal do Paraná (UFPR), através do Programa de Pós-Graduação em Educação Física (PPGEDF), onde estão sendo desenvolvidas pesquisas realizadas pelo Núcleo de Estudos em Políticas Públicas para o Esporte (NEPPE) ${ }^{\mathrm{a}}$, através do grupo Inteligência Esportiva (IE) que tem por objetivo central desenvolver estudos em políticas publicas para o esporte e lazer. Uma dessas políticas é traduzida pelo programa Bolsa Atleta $^{\mathrm{b}}$ do Governo Federal a qual tem sido mapeada pelo Inteligência Esportiva identificando atletas das modalidades esportivas olímpicas contemplados por ela. O programa Bolsa Atleta foi criado no ano de $2005 \mathrm{com}$ a proposta de subsidiar financeiramente atletas de alto rendimento que obtêm resultados nacionais e internacionais ${ }^{1,2,3}$. Busca ainda garantir condições de que os atletas se dediquem, com exclusividade e tranquilidade, aos treinos e competições o que pode ser traduzidos em maiores chances de se obter melhores resultados. Este programa, no ano de 2012, ganhou mais um braço denominado Atleta Pódio com a proposta de subsidiar atletas brasileiros com chances de ganhar medalhas nas Olimpíadas Rio 2016. Se estes são os maiores programas de desenvolvimento de atletas de alto rendimento no Brasil é possível depreender a existência de uma relação de melhores resultados da carreira de atletas no mesmo período de subsídio por aquela política pública?

Através daquela problemática esta pesquisa em tela se propõe, ainda, identificar os 10 melhores atletas da prova de $100 \mathrm{~m}$ rasos masculino e feminino do ranking brasileiro de atletismo, no ano de 2014, visando encontrar relações dos resultados obtidos daqueles atletas dentro do ranking com possíveis subsídios da política pública do Bolsa Atleta e Atleta Pódio, retroagindo até o ano de 1997.

Quando se discute sobre esporte de alto rendimento e deparamos com os melhores atletas das modalidades esportivas, um dos grandes questionamentos realizados, motivo de incompreensão entre os leigos é a da aparente sensação de que aqueles seres humanos que são atletas nasceram para serem campeões e galgaram suas classificações de um momento para o outro ${ }^{4}$. Estudiosos, atletas, treinadores, simpatizantes e os próprios atletas sabem que isto não é verdade, a preparação esportiva representa 0 sistema organizado de um conjunto complexo de fatores ${ }^{5}$, e para isso é de extrema importância que os fundamentos básicos sejam desenvolvidos na infância e juventude ${ }^{4}$. A "Preparação Desportiva a Longo Prazo" (PDLP) possui como objetivo obter uma melhora constante, elevando as exigências de treino e assim obter a máxima eficiência em uma definida idade ${ }^{6}$.

Aliado a isto, estudos têm sido desenvolvidos para encontrar formas de analisar os fatores que determinam o sucesso esportivo internacional tal como o modelo analítico desenvolvido por especialistas De Bosscher et. al. ${ }^{7}$ denominado Sports Policy Factors Leading to International Sporting Success (SPLISS). Segundo os autores nove fatores foram detectados como determinantes do sucesso esportivo situados em dois níveis, entrada e processo. $\mathrm{Na}$ entrada apontam como fator determinante $\mathrm{o}$ apoio financeiro, já o processo é composto por oito pilares dentre os quais: organização e estruturas políticas para o esporte, participação e esporte de base, identificação de talentos e sistema de desenvolvimento, suporte para atletas e pós-carreira, instalações esportivas, desenvolvimento e suporte para técnicos, competições nacionais e internacionais e pesquisa científica. Ainda segundo De Bosscher et. al. ${ }^{7} 0$ suporte financeiro é um dos fatores que compõe o rol de pilares mais importantes para o sucesso esportivo, bem como as políticas públicas influenciam o sucesso esportivo internacional no mesonível.

Já Oakley e Green $7^{8}$ apontam dez fatores relacionados os quais são divididos em aspectos contextuais: (1) cultura de excelência e (2) financiamento adequado; aspectos processuais: (3) compreensão do papel dos diferentes órgãos, (4) simplicidade de administração, (5) sistema eficaz de monitoramento do progresso de atletas, (6) identificação de

\footnotetext{
${ }^{a}$ http://www.nepolítica públicae.ufpr.br/paginas/atividades

${ }^{\mathrm{b}} \mathrm{http}: / /$ www2.esporte.gov.br/snear/bolsaAtleta/sobre.jsp
}

talentos e direcionamento de recursos; (7) sistema de planejamento abrangente para cada esporte e (8) apoio ao estilo de vida; e aspectos específicos: (9) programas competitivos e (10) instalações específicas bem estruturadas.

Devido aqueles e vários outros estudos relacionados Houlihan e Green ${ }^{9}$ chegaram a quatro elementos chave e comuns a todas as análises sendo elas (1) centralidade das instalações de treinamento; (2) apoio financeiro do setor público; (3) integração entre programas de preparação para o treinamento com as oportunidades de competições; e (4) um conjunto de pessoal de apoio especializado.

Com as Olimpíadas em 2016 sediadas no Brasil o Núcleo de Estudos em Políticas Públicas para o Esporte tem mapeado instituições e entidades relacionadas ao esporte com objetivo de desenvolver um panorama a partir das ações de entidades governamentais, buscando, dentre outros objetivos, estabelecer relações de propostas do Projeto Jogos Olímpicos/Paralímpicos -2016 e sua efetivação ${ }^{2,3,10}$.

Com as possibilidades de resultados será possível ampliar os dados e promover a discussão científica às políticas públicas de desenvolvimento do esporte no Brasil, especificamente neste estudo sobre 0 atletismo, permitindo indicar melhores direcionamentos dos recursos financeiros aos atletas suplantando cada vez mais os bancos de pesquisas científicas nas universidades, bem como esclarecer algumas demandas acadêmicas quanto aos acontecimentos políticos atuais e seus planos de aplicação ao desenvolvimento do esporte no Brasil em razão do movimento olímpico ${ }^{11,12}$.

\section{Métodos}

Pesquisa quantitativa, bibliográfica e documental do tipo exploratória $a^{13,14}$ por meio do site da Confederação Brasileira de Atletismo (CBAt) e seu ranking dos atletas desde o ano de 1997. A referida página ainda dispõe de informações divididas por categorias de idade e gênero ${ }^{15}$. Foi selecionado os 10 primeiros colocados masculinos e femininos da prova de $100 \mathrm{~m}$ rasos constantes no ranking da CBAt em dezembro de 2014, tendo como intenção identificar o percurso de rankeamento do atleta ao longo de sua vida esportiva. A pesquisa iniciou ao final do ano de 2014 tendo em vista que não mais haveriam competições e consequentemente alterações nas classificações do ranking e terminou quando cada atleta deixou de aparecer no ranking retroagindo nos anos, até chegarmos no ano de 1997.

Após definidos os atletas a serem mapeados, foi identificado no sítio eletrônico do Ministério do Esporte - Bolsa Atleta ${ }^{c}$ e Atleta Pódio - nos documentos oficiais de divulgação e o banco de dados do Programa Inteligência Esportiva, quais atletas e em que ano foram contemplados pelo benefício do referido programa

Foi identificado o estado de origem e de treinamento no ano de 2014, bem como os estados onde se localizavam os clubes que representavam visando identificar o movimento migratório entre eles. Adotou-se como critério de inclusão a busca em outras provas do atletismo haja vista ser comum competirem na prova de revezamento $4 \times 100 \mathrm{~m}$, por exemplo.

Todos os dados foram organizados em uma planilha do programa Microsoft Office Excel (versão 2007) para análise estatística contendo colunas com descrição de colocação na prova, marca obtida, ano da competição, nome do atleta, prova competida, categoria de idade, data de nascimento, clube representante, origem e local de prova (Estado ou País).

Para análise dos referidos dados foram cruzadas as informações fornecidas pela CBAt através dos rankings identificando $O$ ano dos melhores resultados e em quais deles foram contemplados pelo Programa Bolsa Atleta e Atleta Pódio.

\section{Resultados}

Da análise que compõem os dados coletados verifica-se que os 10 primeiros colocados do ranking brasileiro masculino e feminino adultos da prova de $100 \mathrm{~m}$ rasos do atletismo apareceram no ranking brasileiro da CBAt 476 vezes no masculino do ano de 2003 a 2014 e 705 vezes no feminino do ano de 1999 a 2014. Todos os 10 atletas masculinos e femininos

\footnotetext{
${ }^{\mathrm{c}}$ http://www2.esporte.gov.br/snear/bolsaAtleta/lista Contemplados.jsp
} 
figuraram em outras provas que não os $100 \mathrm{~m}$ rasos como o $60 \mathrm{~m}$ indoor, $75 \mathrm{~m}, 200 \mathrm{~m}, 250 \mathrm{~m}, 400 \mathrm{~m}$, revezamento $4 \times 75 \mathrm{~m}, 4 \times 100 \mathrm{~m}$, medley e salto em distância em diferentes categorias as quais todas as aparições foram contabilizadas neste estudo.

A Norma 12 da CBAt regulamenta as categorias oficiais do atletismo por faixa etária corroborando com as determinações nas Normas e Regras da $\operatorname{IAAF}^{16}$ e da CONSUDATLE (Confederação Sul-Americana de Atletismo) sendo de aplicação obrigatória em todas as provas oficiais conforme tabela 1.

Tabela 1

Categorias oficiais do atletismo.

\begin{tabular}{ll}
\hline Categoria & Idade (no ano da competição) \\
\hline Pré-Mirins & $12-13$ anos \\
Mirins & $14-15$ anos \\
Menores & $16-17$ anos \\
Juvenis & $16-19$ anos \\
Sub-23 & $16-22$ anos \\
Adultos & 16 anos em diante \\
Masters & 40 anos em diante \\
\hline
\end{tabular}

De acordo com a divisão etária estabelecida pela IAAF os atletas pesquisados apareceram em 49,7\% e 41,5\% na categoria adulto feminino e masculino respectivamente, $20,8 \%$ e $30,4 \%$ na categoria sub-23, $15,8 \%$ e $18 \%$ na categoria juvenil, $11 \%$ e $9,8 \%$ na categoria menores e apenas $0,4 \%$ na categoria mirim feminino.

Quanto aos estados onde atualmente vivem e treinam 5 dos atletas masculinos são de São Paulo, 4 do Rio de Janeiro e 1 de Santa Catarina, no feminino 8 são de São Paulo e 2 do Rio de Janeiro (Figura 1) conforme dados referentes as informações constantes no ano de 2014.



Masculino Feminino

Figura 1. Número de atletas por estado.

Evidenciou-se a alternância dos clubes que os atletas representavam ao figurarem no ranking. A partir da figura 2 é possível visualizar de quais estados brasileiros aquelas entidades representadas são oriundas distribuindo 19 dos clubes encontrados no masculino e 32 no feminino.

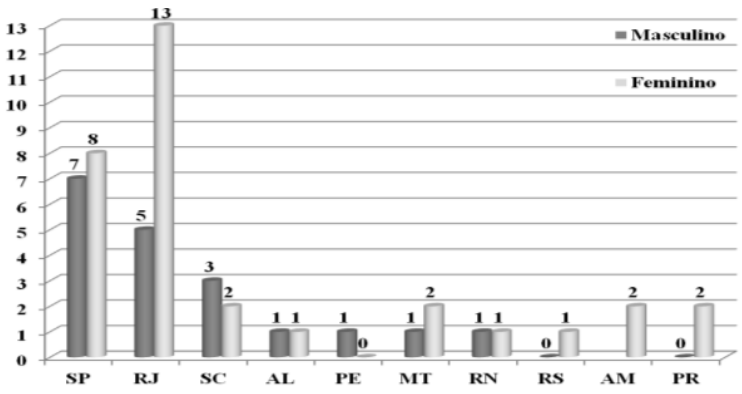

Figura 2. Locais dos clubes representados pelos atletas

Devido a esta grande mudança de clubes pelos atletas verificou-se dentre os 20 que do masculino 1 atleta competiu por um período de tempo sem clube e representou outros 4, 1 atleta permaneceu com o mesmo clube durante todos os anos que apareceu no ranking, 3 atletas representaram 2 clubes, 2 atletas representaram 3 clubes e 3 atletas representam 4 ou mais clubes. No feminino 2 atletas representaram apenas 1 clube, 1 atleta representou 2 clubes, 1 atleta representou 3 clubes, 6 atletas representaram 4 ou mais clubes tendo uma delas figurado no ranking sem representar clube algum (figura 3 ).



Figura 3. Clubes representados pelos atletas no ranking da CBAt.

Os atletas em questão possuem uma média de idade de $23,1 \pm 2,46$ anos no masculino sendo o atleta de menor idade com 20 anos e o de maior 27 , já o feminino $25,6 \pm 3,94$ anos com a menor idade 18 anos e a maior idade com 32 anos, demonstrando maior perenidade das mulheres no ranking em comparação com os homens. Deles 9 figuraram no ranking desde a categoria menores e 1 desde a categoria Sub-23, das mulheres 9 figuram no ranking desde a categoria menores e 1 desde a categoria mirim. Ainda, do masculino o tempo médio de permanência no ranking foi de $7 \pm 2,21$ anos sendo 0 atleta com menor perenidade permanecido 4 anos enquanto o de maior 10 anos, já no feminino o tempo médio de permanência no ranking foi de $9,8 \pm 4,41$ anos sendo a atleta com menor perenidade figurado 1 ano e a de maior 16 anos.

Ao analisar o melhor resultado de cada atleta na prova de $100 \mathrm{~m}$ rasos verificou-se que no masculino $60 \%$ obtiveram seu melhor tempo no ano de 2014, 10\% em 2013, 20\% em 2012 e $10 \%$ em 2009 todos obtidos em provas no Brasil, sendo este último o corredor de maior idade. No feminino $40 \%$ obteve o melhor índice em 2014, 50\% no ano de 2013 e 10\% no ano de 2012 sendo que $30 \%$ destes em competições fora do Brasil.

No que diz respeito ao Programa Bolsa Atleta, os documentos oficiais ${ }^{d}$ demonstraram que apenas 1 das atletas não foi contemplada, das outras, 9 receberam o incentivo em 2013, 4 das mesmas atletas em 2012 e apenas uma no ano de 2014. Ainda, 4 das atletas receberam o incentivo em três anos, sendo duas delas por anos consecutivos. Outras 4 atletas receberam em dois anos - sendo uma no ano de 2005 e outra em 2007 - e uma delas apenas uma vez.

No masculino 6 dos 10 atletas receberam o incentivo desde a criação do Programa em 2005 sendo 4 no ano de 2014, 5 em 2013 e 2012. No que diz respeito a perenidade 4 deles obtiveram o incentivo por 2 anos consecutivos e 2 deles por três anos consecutivos:

Por fim, verificamos que em relação ao Programa Atleta Pódio apenas o atleta masculino que obteve a quinta colocação no ano de 2014 foi contemplado e no feminino as atletas femininas que estavam na primeira, terceira e quarta colocações no ranking CBAt, na prova de $100 \mathrm{~m}$ rasos no ano de 2014 , foram contempladas

\section{Discussão}

Em análise dos referidos dados verifica-se que a predominância dos atletas se dá na região sudeste com $50 \%$ e $80 \%$ masculino e feminino, respectivamente, do estado de São Paulo, $40 \%$ e $20 \%$ do estado do Rio de Janeiro e apenas $10 \%$ do masculino advindo da região sul (Santa Catarina) demonstrando que o eixo RJ - SP é o grande polo esportivo nesta modalidade, corroborando com o grande evento esportivo que acontecerá no Brasil, Olimpíadas Rio 2016 $6^{15,17}$. Em virtude deste mega evento esportivo muitos projetos de desenvolvimento estão sendo realizados no Rio de Janeiro como as Vilas Olímpicas, complexos de treinamento esportivos, pavimentação de estradas, recuperação de bairros históricos e Centros Integrados Profissionalizantes que auxiliaram no desenvolvimento do esporte ${ }^{18}$. O campo esportivo é caracterizado em uma inter-relação entre oferta e a demanda de

\footnotetext{
${ }^{\mathrm{d}}$ Retirado das portarias de publicação dos atletas contemplados com o Bolsa Atleta desde que foi criado em 2005 até o ano de 2014 através do sítio http://www2.esporte.gov.br/snear/bolsaAtleta/listaContemplados. jsp, acesso em 03 mar. 15.
} 
produtos e serviços ${ }^{19}$ e nesta linha de raciocínio São Paulo e Rio de Janeiro com a quantidade de clubes (Orcampi, Brasil Food, BM\&F Bovespa, AD Criciúma, etc.) financiadores de atletas de atletismo possui uma oferta dentro desta modalidade maior do que em outras regiões do Brasil.

No que diz respeito aos clubes também existe predominância destes no eixo RJ - SP representando cerca de $36 \%$ e $25 \%$ em São Paulo pelo masculino e feminino, respectivamente, e $21 \%$ e $34 \%$ dos clubes no Rio de Janeiro.

Tendo uma idade média de 23,1 anos em 2014 para os homens e 25,6 anos para as mulheres com uma média de permanência no ranking de 7 e 9,8 anos respectivamente, ambos iniciam sua aparição profissional no ranking por volta dos 14-15 anos de idade. Com estes dados as mulheres demonstraram iniciar sua aparição profissional na modalidade mais jovem e permanecerem por mais tempo nela. Enquanto o atleta masculino mais perene no ranking esteve durante 11 anos no feminino foi de 15 anos, assim como o de maior idade 27 e 32 respectivamente. Outro fator que pode contribuir para esta questão se traduz no número de aparições no ranking sendo de 476 no masculino e 705 no feminino, respectivamente, $48 \%$ mais do que os atletas homens. Este grande lapso temporal na carreira do atleta pode ser dividido em três grandes momentos sendo o de inserção na modalidade esportiva e mundo competitivo, desenvolvimento de sua performance e a manutenção de seus resultados, dentre os quais este último merece atenção especial no campo das políticas públicas, visto que os incentivos devem ser contínuos e levada em consideração a caminhada profissional do atleta, o que permite um diagnóstico mais seguro e justo àqueles que contribuem efetivamente para o desenvolvimento do esporte e possuem chances reais de rendimento ${ }^{20}$.

Ao analisar as melhores marcas obtidas percebe-se que estas ocorreram quase na totalidade dos atletas nos anos de 2013 e 2014 quando possuíam entre 21 e 23 anos de idade. Ao sobrepormos o ano de melhor marca na prova de $100 \mathrm{~m}$ dos atletas masculinos e femininos com o período que foram beneficiados com o Programa Bolsa Atleta percebe-se que tendo sido contemplados nos anos de 2012, 2013 e 2014, podemos suscitar que talvez não seja uma relação de causa e efeito entre elas, mas que coincidentemente ambos aconteceram no mesmo tempo.

Já no programa Atleta Pódio o masculino apresentou apenas um contemplado no ano de 2013 e que obteve seu melhor tempo no ano de 2009, sendo o atleta de maior idade e mais perene no ranking da CBAt, apesar de ter sido terceiro melhor atleta no ranking em 2013. No feminino constatamos que as atletas foram contempladas em $2013 \mathrm{com}$ ambos os programas, eram primeira, terceira e quarta colocadas naquele ano e duas detinham suas melhores marcas.

\section{Conclusão}

Dos 20 atletas aqui representados 16 têm sua melhor marca nos anos de 2013 e 2014, bem como foram contemplados, quase em sua totalidade, com o Programa Bolsa Atleta no mesmo ano em que obtiveram seu melhor resultado, demonstrando que existe relação entre melhores resultados com financiamento ${ }^{7,8,9}$

Se o Brasil quer fazer frente aos mega eventos esportivos ${ }^{11}$ e deixar ou resgatar um legado ${ }^{12,21}$ para o país é necessário estabelecer metas de ação para o desenvolvimento do esporte desde sua categoria de base até o aprimoramento na fase adulta, amadurecendo e investindo na cientifização da educação física, valorização do profissional da área, permitindo a prática social dissociada de classes, do esporte espetáculo/consumo e da prática enquanto mecanismo de fuga cultural ${ }^{22}$, visando uma prática acessível a todos sem compromisso e então extrair àqueles que objetivam o esporte de rendimento.

$O$ fato de algumas das atletas terem projetado seus melhores resultados em competições fora do Brasil podem ter auxiliado a garantirem permanência no Programa Bolsa Atleta por mais tempo, diferentemente dos homens ${ }^{23}$.

Se o pilar financeiro apontado por Houlihan e Grenn ${ }^{9}$ citado neste estudo pode demonstrar que o apoio pelo setor público, através do Programa Bolsa Atleta, aos atletas de atletismo da prova de $100 \mathrm{~m}$ rasos entre os melhores do ranking no ano de 2014 corroborou para que obtivessem seus melhores resultados, também os outros 3 pilares que o sustentam - (1) centralidade das instalações de treinamento; (2) integração entre programas de preparação para o treinamento com as oportunidades de competições e (3) um conjunto de pessoal de apoio especializado - merecem atenção em outros estudos como este.

Assim é necessária a atenção com pesquisas como esta que buscam realizar um diagnóstico específico para discutir a política e gestão do esporte de alto rendimento em um contexto com suporte exploratório que busca prognóstico analítico, principalmente frente ao pilar financeiro tido como importante para o efetivo desenvolvimento do esporte de alto rendimento.

\section{Referências}

1. Nunes, CC, Cunha GSVT. Estado e as políticas públicas esportivas:o contexto brasileiro. Revista da Alesde. 2014 set; 4(2): 4-15.

2. Corrêa, JA. et al. Financiamento do esporte olímpico de verão brasileiro: mapeamento inicial do programa "Bolsa-Atleta" (2005-2011). Pensar a Prática. 2014 out./dez; 17(4).

3. Figuerôa, KM, Mazzadri FM, Silva MM. RIO 2016: possibilidades desafios para o esporte brasileiro. Motrivivência. 2013 dez.; 25(41): 140154

4. Bohme MTS. O Treinamento a longo prazo e o processo de detecção, seleção e promoção de talentos esportivos. Revista Brasileira de Ciências do Esporte. 2000. 21(2).

5. Mazo JZ, Silva CF, Lyra VB. As mulheres no cenário do associativismo esportivo em Porto Alegre/RS na transição do século XIX para o XX: alternativas de sociabilidade e lazer para elas. Licere set.; 13(3).

6. Cafruni C, Marques A, Gaya A. Análise da carreira desportiva de atletas das regiões sul e sudeste do Brasil. Estudo dos resultados desportivos nas etapas de formação. Revista Portuguesa de Ciências do Desporto. 2006 jan.; 6(1): 55-64.

7. De Bosscher V, De Knop P, Van Bottenbrug S, Bingham J. Explaining international sporting success: An international comparison of elite sport systems and policies in six countries. Sport Management Review. 2009: 12: 113-36.

8. Green, M, Oakley B. Elite sport development systems and playingtowin: Uniformity Diversity in inter- national approaches. Leisure Studies. 2001 20(4): 247-267.

9. Houlian B, Green M. Comparative elite Sport development: systems, structures and public policy. Elsevier. 2008.

10. Souza DL, PAappous S. Legados esportivos de megaeventos esportivos: uma revisão de literatura. Motrivivência. 2013 dez.; 25(41): 42-56.

11. Mohammadi S, Keyvan AD. The necessity of considering the challenges facing Olympic Movement. DOI: 10.4100/jhse.2011.61.01. Journal of Human Sport \& Exercise. 2011; 6.

12. Corral DC et. al. Principles of the Olympic Movement. Journal of Human Sport \& Exercise. 2010; 5(1): 3-14, 2010. DOI: 10.4100/jhse.2010.51.02

13. Gomes AC. Treinamento desportivo: estruturação e periodização. Porto Alegre: Artmed, 2002

14. Gil AC. Como elaborar projetos de pesquisa. São Paulo: Atlas, 2008.

15. Brasil. Confederação Brasileira de Atletismo. Norma 12 Categorias oficiais do atletismo brasileiro por faixa etária. Disponível em: $<$ http://www.cbat.org.br/atletismo/Norma12 Cat Faixas Etarias Oficiais.p $<$ http://www.cbat.org.br/atletismo/Nor

16. Brasil. Confederação Brasileira de Atletismo. Rankings. Disponível em: <http://www.cbat.org.br/estatisticas/ranking outros anos.asp>. Acessoem: 16 de mar. 2015

17. Coakley J, Souza DL. Sport mega-events: Can legacies and development be equitable and sustainable? Revista Motriz. 2013 jul./sep; 19(3).

18. Palangana IC. Desenvolvimento e aprendizagem em Piaget e Vygotsky. São Paulo: Summus Editorial, 2001.

19. Bourdieu P. Deporte y clase social. In: BROHM, Jean Marie et al. Materiales de sociologia del deporte. Madri: Edicione de la Piqueta. 1993.

20. Mascarenhas F. Megaeventos Esportivos e Educação Física: alerta de tsunami. Movimento. 2012 jan./mar; 18(1)

21. Perez VR, Minguet JLC, Freire MG. Sports Management services: the dimensions of quality. Journal of Human Sport and Exercise. 2010; 5(2): 295-306.

22. Bourdieu P. Questões de sociologia. Rio de Janeiro: Marco Zero. 1983

23. Vidal $A M$ et al. Sociological context in Spanish high level athletics by gender. Journal of Human Sport and Exercise. 2010; 5(1): 24-33 